\title{
OCKHAM E A FUNÇÃO DA ABSTRAÇÃO ${ }^{1,2}$
}

\section{Rodrigo Guerizoli (UFRJ) $)^{3}$}

rguerizoli@ufrj.br

[...] los Colegios de Cartógrafos levantaron un
Mapa del Imperio, que tenía el tamaño del
Imperio y coincidía puntualmente con él. Me-
nos Adictas al Estudio de la Cartografía, las
Generaciones Siguientes entendieron que ese
dilatado Mapa era Inútil y no sin Impiedad lo
entregaron a las Inclemencias del Sol y de los
Inviernos.
J. L. Borges, Del rigor en la ciencia

Resumo: A abstração foi tradicionalmente considerada um elemento essencial de qualquer teoria do conhecimento que negasse que somos capazes de possuir uma apreensão intelectual imediata das coisas materiais. Desde um ponto de vista histórico, porém, esse cenário de alternativa - ou abstração ou apreensão intelectual imediata das coisas materiais - não foi assumido por diversos autores do século XIV. O objetivo do presente estudo é elucidar o como e o porquê de um desses autores, Guilherme de Ockham (ca. 12851347), ter empregado ambos, intuição e abstração, em sua teoria dos mecanismos da cognição humana. Para que se cumpra tal meta serão analisados diversos textos de Ockham e de seus intérpretes.

Palavras-chave: abstração, intuição, Guilherme de Ockham.

1.

Se os entes materiais nos fossem imediatamente inteligíveis,

\footnotetext{
${ }^{1}$ Recebido: 14.11.2010/Aprovado em 23.04.2011/Publicado on-line: 07-09-2011.

${ }^{2}$ Agradeço ao CNPq e à FAPERJ pelo apoio financeiro à pesquisa que está na base do presente artigo.

${ }^{3}$ Rodrigo Guerizoli é Professor Adjunto do Departamento de Filosofia da Universidade Federal do Rio de Janeiro, Rio de Janeiro, Brasil.
} 
a abstração seria supérflua e, aliás, contraproducente. Afinal, cada ato de abstração implicaria numa perda cognoscitiva frente à apreensão primeira dos indivíduos. Fosse a abstração supérflua, supérflua seria também toda ciência, todo saber guiado por noções abstratas, e com isso cairia por terra todo o prestígio da metafísica, habitus que encarna o ideal de realização pelo saber. Não que tal ciência se tornasse impossível. Na verdade, ela apenas deixaria de ser buscada. Isso nos faria querer o abstrato se pudéssemos, na raiz mesma de nosso contato com as coisas, captar o mundo em sua concretude? Por que preferiríamos a caricatura dos conceitos aos detalhes de noções ao mesmo tempo inteligíveis e retentoras dos traços mais particulares das coisas?

Foi com base numa tal articulação entre inteligibilidade do ente material, papel da abstração e dignidade da metafísica que por mais de uma vez se pôs à mostra o problema de toda defesa da apreensão direta dos indivíduos materiais. Comparada a outros esforços no mesmo sentido, essa reductio tem a vantagem de não se perder em questões particularmente espinhosas, como a da cognoscibilidade da matéria ou a da pluralidade das formas. Ao contrário, assume-se, por hipótese, a intelecção direta dos singulares materiais e mostra-se que daí não decorre senão a perda de tudo o que possa justificar, de modo minimamente razoável, o porquê de tendermos naturalmente à edificação de saberes que, no fim das contas, nos diria menos sobre o mundo do que aquilo que aprenderíamos sobre ele imediatamente e sem qualquer esforço.

Historicamente, contudo, a contraposição entre inteligibilidade dos entes materiais e abstração nem sempre se impôs tão nitidamente, e não foram poucos os que a partir 
do último quarto do século XIII retiveram a noção de abstração, embora rejeitassem que nossa intelecção dos indivíduos materiais fosse apenas indireta.

Elaborada por Tomás de Aquino, presente em Henrique de Gand e sob uma roupagem toda própria em Duns Scotus, a tese da intelecção indireta do singular se estabelece como alternativa a um aristotelismo supostamente ortodoxo que, apoiado na ideia de que o intelecto apreende apenas de modo abstrato, considerava de todo impossível a apreensão intelectual do singular material (cf. Day 1947, 14 34; Klubertanz 1952; Bérubé 1964, 41-68/134-175; Putallaz 1991, 119-121). Contra tal perspectiva, Tomás sublinha que o intelecto é capaz de retraçar, a contrapelo, o caminho que levou da apreensão sensível ao conceito, redescobrindo, por meio de reflexão e de uma série de patamares de atenção - inicialmente com respeito a seu próprio ato, em seguida à espécie inteligível e, por fim, ao fantasma - o ente material que esteve na origem daquela intelecção:

[...] mas indiretamente e por uma certa reflexão também pelo intelecto, que não se utiliza de um órgão, (a alma) conhece os singulares, na medida, a saber, em que a partir de seu objeto próprio retorna ao conhecimento de seu ato, donde retorna à espécie, que é princípio da intelecção, e daí procede na consideração do fantasma, a partir do qual uma tal espécie é abstraída; e assim, pelo fantasma, conhece o singular ${ }^{4}$. (AQUINO 1871-1880, IV Sent, d. 50, q. 1, a. 3)

Vários autores, porém, viram na apreensão intelectual indireta ou, como Tomás (1970, De Ver. q. 2, a. 6) também formula, no conhecimento acidental do singular, o resultado de uma exegese equivocada de Aristóteles ou,

\footnotetext{
${ }^{4}$ Um farto dossiê de passagens de Tomás sobre a intelecção indireta dos singulares é oferecido por Bérubé (1964, p. 55-60).
} 
alternativamente, como uma posição incompatível com certas exigências de ordem filosófica ou teológica. Com efeito, eles se consideravam capazes de mostrar de modo convincente que nossa intelecção do singular é direta. Mas o interessante é que isso não os tornava automaticamente refratários à noção de abstração. Com efeito, simplesmente não lhes parecia haver dilema entre intelecção direta dos indivíduos materiais, de um lado, e abstração, de outro. No que segue eu gostaria de examinar mais de perto a posição de um desses autores, Guilherme de Ockham (ca. 12851347), buscando esclarecer o porquê de ele, sob a égide da apreensão intelectual direta do singular material, continuar a empregar a linguagem da abstração.

\section{2.}

Dentre a literatura que trata do papel atribuído à abstração em autores medievais simpáticos à tese da intelecção direta dos indivíduos materiais, o tomo de abertura do clássico $\mathrm{O}$ ponto de partida da metafísica, de J. Maréchal [1964 (1. ed. de 1922)], figura como um verdadeiro paradigma de utilização da estratégia crítica que há pouco apresentei. Mas a obra de Maréchal vai mais longe. Com efeito, nela vem elaborada toda uma interpretação do sentido que teria sido necessário atribuir à noção de abstração para que se pudesse compatibilizá-la com uma teoria do conhecimento que incluía a apreensão intelectual direta dos indivíduos materiais e, desse modo, mantê-la no léxico filosófico da época. Tal mudança de enfoque equivaleria, porém, segundo Maréchal, a atribuir à abstração um sentido totalmente diverso daquele pelo que se prestava contas, tanto em solo grego quanto em Tomás de Aquino, do processo de formação e 
utilização de nossos conceitos.

Especificamente, o problema desse processo de ressignificação da noção de abstração, aponta Maréchal, reside no fato de que o resultado obtido não mais exprime uma operação que se desenvolve no patamar mais básico de nossa atividade cognoscitiva. Com efeito, num contexto em que o individual é inteligível, ao se falar de abstração não mais se trataria de abordar uma operação "natural e primitiva, operada imediatamente sobre o sensível apenas pelo fato da imaterialidade do agente intelectual" (MARÉCHAL 1964, 113). Não mais se trataria de uma aphairesis, mas, ao contrário, de "uma abstração refletida, operando uma triagem formal nos conceitos singulares" (MARÉCHAL 1964, 174/227). Tratar-se-ia, em verdade, de uma indução, uma epagoge. Contudo, adverte Maréchal, admitir que nossos universais se formam sobre induções, por natureza incompletas, significa aceitar que toda justificação da objetividade de nossas abstrações fica a meio caminho. Em contraposição, no quadro em que se concede a ininteligibilidade direta do singular material, a abstração atua como um procedimento cognoscitivo primário, responsável pela própria gênese de todos os nossos conceitos. E apenas tal teoria, aliada a um realismo que reconhece o próprio mundo como base sobre a qual opera nosso esforço abstrativo, pode, segundo Maréchal, legitimar a objetividade de nosso conhecer.

3.

Parece que a posição de Maréchal vale, de fato, como uma crítica ao uso feito por certo domínio da filosofia moderna da ideia de abstração. Com efeito, o estudioso belga se con- 
trapõe à compreensão da abstração como uma operação que extrai o fator comum de uma série de itens de antemão inteligidos, criticando, assim, a ideia de um procedimento que generaliza sobre a intelecção de vários indivíduos. Tal compreensão significaria, em seu juízo, um desvio face ao significado primitivo de abstração, que indicaria uma operação que isola e atualiza o aspecto inteligível de um indivíduo, possibilitando toda e qualquer intelecção da natureza das coisas.

Nesse sentido, seria decerto pertinente ler-se a crítica marechaliana à luz, por exemplo, das reflexões de John Locke, que de fato embasa sua etiologia das noções universais no procedimento de comparação entre noções particulares:

[...] a mente faz as Idéias particulares, recebidas dos Objetos particulares, tornarem-se gerais [...]. Isto é chamado ABSTRAÇÃO, pelo que Idéias tomadas de Seres particulares tornam-se Representantes gerais de tudo o que é da mesma espécie. [...] Assim, tendo a mesma Cor sido observada hoje no Giz ou na Neve, a qual a Mente recebera ontem do Leite, ela considera aquela Aparência apenas, faz-lhe um representante de tudo o que é daquela espécie ${ }^{5}$. (LOCKE 1975, II.11.9)

Não é evidente, contudo, que a crítica de Maréchal seja em bloco pertinente quando dirigida aos autores medievais. Em particular, não é óbvio que ela consiga pôr em xeque o modo como um dos principais responsáveis pela construção de uma teoria do conhecimento baseada na apreensão intelectual do singular material, Guilherme de Ockham, lança

\footnotetext{
${ }^{5}$ Que a abstração lockeana tenha por base uma série de ideias que de algum modo nos são previamente acessíveis é amplamente aceito. Cf., p. ex., Chappell (1994, 39ss.), Lowe (1995, 156), Jolley $(1999,50)$. Cf. tb. Kant [2002, 187 (AK94)]. Uma conexão sistemática entre Locke e Ockham através dos universais, que não aborda o ponto aqui em pauta e que enxerga em Locke uma resposta a certas dificuldades do nominalismo ockhamiano, oferece Tweedale (1998).
} 
mão da noção de abstração.

Com efeito, não obstante atribuir um papel-chave em sua teoria do conhecimento à tese da inteligibilidade direta dos indivíduos materiais, Ockham, contradizendo uma imagem ainda não de todo ausente do panorama medievista, a de um autor que "considera suficiente o conhecimento intuitivo e rejeita o conhecimento abstrativo, que julga uma ficção inútil ou, no máximo, um conhecimento intuitivo ainda imperfeito" (WEBER 1990, 11), pensa ser indispensável que se reconheça em termos positivos a capacidade abstrativa do intelecto. E tal reconhecimento é exigido principalmente em meio ao tratamento de dois temas: na justificação de um aspecto específico de nossas competências, qual seja, o fato de amiúde formarmos proposições contingentes cuja verdade não nos é evidente, e no desdobramento explicativo da gênese de nossas noções universais.

4.

Se é contra o caráter generalizante que orienta certa leitura da noção de abstração que se insurge Maréchal, há, de fato, trechos da obra de Ockham que, se não justificam, ao menos parecem dar algum lastro à sua inclusão no rol de alvos do estudioso belga. Ao comentar, por exemplo, a maneira como Aristóteles diferencia a matemática da física, Ockham (1974-1988, IV, 264) indica que em toda ciência tem lugar a operação pela qual "o intelecto abstrai o universal dos singulares". Outra passagem, mais frequentemente citada, encontra-se no prólogo da Ordinatio e figura como um locus classicus da compreensão ockhamiana de abstração. Nela é afirmado que, num sentido, a ideia de notitia abstractiva "diz 
respeito a algo abstraído de muitos singulares e, nesse sentido, a cognição abstrativa não difere da cognição de algo abstraível de muitos" (OCKHAM 1967-1986, I, 30).

Ao reconhecer o universal como algo abstraído "dos singulares", "de muitos singulares" ou simplesmente "de muitos", Ockham abre a possibilidade de que se interprete sua teoria através de uma ótica generalista. Mas tudo ainda depende de como lemos suas frases. Se optamos por uma leitura em "sentido composto" (sensus compositus), em que "cinco é igual a dois e três" é verdadeiro, nos aproximamos da crítica marechaliana: termos abstratos teriam por base determinados conjuntos de singulares. Se, ao contrário, privilegiamos uma leitura em "sentido dividido" (sensus divisus), em que "cinco é igual a dois e três" é falso, reconhecemos nas expressões de Ockham apenas uma característica inconteste dos universais: o fato de cada um poder ser formado a partir de diferentes indivíduos, isto é, desde qualquer uma de suas instâncias ou de seus significa$t a^{6}$.

O apelo a outras passagens de Ockham pode esclarecer a dúvida sobre a interpretação dos trechos que parecem fornecer apoio à crítica marechaliana. Com efeito, tratando em sua Reportatio - obra de juventude (1317-1318), que nunca chegou a receber uma revisão - da questão "se isto deve ser aceito: Deus tornou-se homem”, Ockham argumenta explicitamente em favor da tese de que de uma

\footnotetext{
${ }^{6}$ Sobre a distinção sensus compositus/sensus divisus cf. Maierú (1996) e Kretzmann (1981), que analisa o tratado De sensu composito et diviso (ca. 1335) de Guilherme de Heytesbury, em que se distingue "A et B possunt esse verae in C instanti" de "A propositio potest esse vera in C instanti, et $B$ propositio potest esse vera in $C$ instanti". Uma passagem suplementar, explicitamente aludida por Maréchal $(1964,227)$, apenas confirma a ambiguidade para a qual se aponta: "Alguém que vê intuitivamente uma brancura, ou duas brancuras, delas abstrai a brancura em comum enquanto espécie" (OCKHAM 1974-1988, VIII, 175).
} 
noção apreendida diretamente de um indivíduo pode-se chegar à cognição comum de outro indivíduo:

[...] pela cognição (notitia) incomplexa de uma brancura que vi sou levado à cognição incomplexa de uma outra brancura, que nunca vi; isso porque abstraio da primeira brancura o conceito de brancura, que diz indiferentemente respeito a esta brancura e àquela. Do mesmo modo, a partir de um acidente qualquer que vi abstraio o conceito de ente, que não diz mais respeito àquele acidente do que a uma substância, nem mais à criatura do que a Deus. (OCKHAM 1967-1986, VI, 342)

Deixando de lado o aspecto do texto que se relaciona com o debate acerca da univocidade da noção de ente, essa passagem recolhe uma posição que Ockham não modificará ao longo de sua carreira. Os conceitos mais universais, os communissima da tradição aviceniana, não se formam através de um processo indutivo: basta a cognição de um acidente ou de uma substância para que, por abstração, os engendremos (cf. OCKHAM 1967-1986, II, 482). Analogamente, no outro extremo, as noções menos universais, ou seja, as ultimamente específicas, tampouco são obtidas por um procedimento indutivo: basta que se dê a cognição de uma brancura individual para que se seja levado à cognição em comum de qualquer outra brancura individual. Completando o quadro, a Suma de lógica, situada no final da série de escritos lógicos-filosóficos de Ockham (1323), retoma o tema no âmbito de uma discussão sobre as definições. Muda-se o exemplo, fala-se de "homem", mas a lição da Reportatio permanece: "[...] um homem é de início conhecido por um sentido particular, em seguida aquele mesmo homem é conhecido pelo intelecto, e sendo conhecido ganha-se uma cognição geral e comum com respeito a todo homem. E essa cognição é chamada de conceito, intenção, 
paixão [...]" (OCKHAM 1974-1988, I, 557) .

Essas passagens dão conta de mostrar que Ockham reconhece a capacidade abstrativa do intelecto como uma habilidade cujo desempenho dispensa aquela base plural requisitada pelas generalizações. $\mathrm{O}$ contato sensorial com um único indivíduo, sua intuição por parte dos sentidos, não é para ele apenas o ponto de partida de uma apreensão intuitiva intelectual desse indivíduo. Tal encontro também naturalmente deslancha apreensões abstrativas e universais.

É, portanto, possível constatar no quadro epistemológico ockhamiano a presença de ao menos um elemento inconciliável com a descrição proposta por Maréchal da relação entre intuição direta do singular e teoria da abstração: o receio de que a defesa da apreensão direta do individual por parte do intelecto torne ipso facto supérfluo todo apelo à abstração encontra aí um renitente contraexemplo, que não se restringe, como se pode suspeitar com relação a Locke, a uma questão de vocabulário. Em Ockham, com efeito, é nítida a ideia de que a gênese do universal decorre de uma operação feita sobre um único indivíduo. Basta uma apreensão intuitiva, individual, para que venha a surgir aquela outra modalidade de apreensão, a cognição abstrativa.

\section{5.}

Analisando a situação desde um ponto de vista mais geral, nos deparamos com o conflito entre, de um lado, uma interpretação que considera poder fazer decorrer da tese da intelecção direta do individual uma série de consequências

\footnotetext{
${ }^{7}$ Cf. também Quodlibeta Septem IV.17 (OCKHAM 1967-1986, IX, 385): “[...] conceptus speciei potest abstrahi ab uno individuo" ["[...] o conceito específico pode ser abstraído a partir de um único indivíduo"] e Panaccio $(1992,71)$.
} 
particularmente nefastas para qualquer pretensão de legitimação do conhecimento e, de outro, a posição histórica de um autor que acolhe o antecedente assumido pelo intérprete, mas não se vê por isso impelido a consentir nas implicações por aquele vaticinadas.

Parece que, dado tal quadro, o diálogo deve seguir numa das seguintes direções: ou bem autor e intérprete deduzem corretamente a partir da premissa que assumem, e nesse caso o conflito reside nos modos implicitamente distintos como cada um deles compreende aquele dado inicial; ou bem algum deles não levou corretamente a termo o processo dedutivo e enveredou por uma trilha cujos resultados não se encontram devidamente respaldados.

Ao retraçar a posição de Duns Scotus sobre nossa cognição dos singulares, Camille Bérubé descobre com respeito ao Doutor Sutil uma tensão análoga à que identificamos entre a leitura marechaliana e Guilherme de Ockham. E no veredicto de Bérubé tal tensão é fruto de uma interpretação enviesada por parte de Maréchal da tese de Scotus sobre a intelecção do individual. Numa áspera apreciação, que insere Maréchal em certa linhagem de historiadores "talvez mais determinados em construir a história a priori do que em perseverar na leitura dos textos" (BÉRUBÉ 1964, 154), Bérubé ataca na reconstrução proposta pelo belga o que em Scotus simplesmente não se encontraria, a saber, a tese de que "a individualidade dos objetos sensíveis nos é imediatamente inteligível” (MARÉCHAL 1964, 161). Faz-se para isso alusão a diversos textos em que Scotus não apenas re-

\footnotetext{
${ }^{8}$ Cumpre, porém, levar em conta a lucidez de Maréchal quanto ao seu intento: "[...] não pretendemos fazer trabalho de historiador; nossas monografias têm menos o objetivo de reconstituir materialmente a doutrina formulada por tal ou tal filósofo do que o de torná-la inteligivel em seus traços essenciais, amarrando-a a seus pressupostos lógicos" (MARÉCHAL 1964, 7).
} 
jeita tal tese, dizendo que atualmente apreendemos os singulares somente indiretamente e por meio de conceitos que exprimem o conjunto de suas propriedades, mas vai inclusive além, negando também aos sentidos qualquer cognição direta (cf. BÉRUBÉ 1964, 156-165).

Contudo, em se tratando de Ockham, uma estratégia como a usada por Bérubé parece não produzir os mesmos efeitos. Isso porque, não obstante se equivoque ao atribuir a Scotus a inteligibilidade atual e imediata dos indivíduos materiais, ao transpor tal juízo para o exame da epistemologia ockhamiana graças à corajosa hipótese de que Scotus, "o sincero aristotélico, [...] não se encontrará, no fim das contas, separado de Ockham senão pela precária barreira de uma afirmação realista mal justificada; pois Ockham, podese dizer, é Duns Scotus menos o realismo dogmático dos universais" (MARÉCHAL 1964, 212/219), a interpretação de Maréchal passa a fazer jus a seu objeto. Efetivamente, a intelecção atual e direta do singular material consiste num tópico essencial da explicação ockhamiana do conhecimento.

É na polêmica em torno ao primum cognitum que a tese ockhamiana da apreensão intelectual do singular, que para Maréchal finca raízes numa temerária transposição da experiência sensível à inteligência, vem particularmente à tona. Trata-se de fato de um ponto nodal da obra de Ockham, através do qual circulam três linhas de força de seu quadro epistemológico: a defesa de que "o primeiro ato realizado pelo intelecto é a cognição intuitiva daquele mesmo singular que é apreendido pelos sentidos" (OCKHAM 19671986, II, 481), a denúncia de pontos presumivelmente inconsistentes dos ensinamentos de Tomás de Aquino e de Henrique de Gand sobre o tópico e, por fim, a elaboração 
de uma exegese de Aristóteles que, divergindo do quadro habitual, o apresente como um aliado teórico.

Assim, o que ao fim e ao cabo se obtém é um vínculo de teses de todo imprevisto por Maréchal. Longe de instituírem um dilema, intuição e abstração, intelecção direta do singular e aphairesis fundada na apreensão de um indivíduo convivem lado a lado na teoria ockhamiana do conhecimento. É evidente, porém, que a credibilidade dessa teoria, para a qual "nosso intelecto, inclusive no estado atual, pode possuir com respeito ao mesmo objeto sob a mesma razão duas cognições incomplexas especificamente distintas, uma que pode ser dita intuitiva e outra abstrativa" (OCKHAM 1967-1986, I, 15), depende de que se possa dissipar a seguinte dúvida: por que fazer apelo à abstração no interior de um quadro teórico que não encontra na constituição dos indivíduos um elemento refratário à sua intelecção? Pois, de fato, concordaria Maréchal, aquelas teorias não são logicamente incompatíveis; mas isso não é suficiente para que se torne interessante - ou econômico do ponto de vista teórico - encaixá-las sob o mesmo esquema.

6.

Rejeitando qualquer alusão a uma barreira cognoscitiva objetivamente imposta pela constituição das coisas, a justificação ockhamiana da abstração é elaborada desde um viés por assim dizer subjetivo e regressivo, principiando pela avaliação do saber veiculado pela apreensão intuitiva. Tal estratégia, que destoa do enfoque tradicionalmente dado à questão, envolve de início a pergunta sobre o tipo de juízo que, tendo por base a intuição, o intelecto é capaz de produzir. Tratando do tema em sua Reportatio, Ockham 
descreve o alcance da cognição intuitiva do seguinte modo:

[...] aquela pela mediação da qual se conhece que uma coisa existe, quando existe, e que não existe, quando não existe. Pois, quando apreendo perfeitamente algum par de extremos de modo intuitivo, posso imediatamente formar um complexo pelo qual tais extremos se encontram unidos ou desunidos e facultar-lhe ou não o assentimento. Por exemplo, se vejo intuitivamente um corpo e uma brancura, (meu intelecto) pode formar este complexo: "um corpo existe" ou "algo branco existe" ou "um corpo é branco"; e, formados esses complexos, o intelecto imediatamente lhes faculta assentimento. (OCKHAM 1967-1986, V, 256-257)

A função característica da cognição intuitiva consiste em ser base necessária à formação e asserção de juízos contingentes verdadeiros. Restringindo nossa atenção ao que ocorre segundo o curso natural das coisas (de potentia ordinata), e deixando intocado o polêmico tópico da intuição dos inexistentes (cf. Boehner 1943 e Karger 1999), podemos dizer que a cognição intuitiva é causa parcial do assentimento a uma proposição afirmativa, verdadeira e existencialmente comprometida, que pode ter tanto a forma de uma proposição de segundo adjacente quanto a de um juízo de inesse. Descrevendo a situação desde outro ponto de vista, quando a intuição dos singulares causa, junto com a presença da coisa, a formação e o assentimento a proposições afirmativas (cf. OCKHAM 1967-1986, V, 256-257) dá-se a gênese de um conhecimento que Ockham chama de "conhecimento evidente" e que corresponde, nessa sua forma específica, ao saber sobre proposições verdadeiras não analíticas naturalmente causado pela apreensão de seus termos ${ }^{9}$.

É possível ensaiar a partir desse quadro uma resposta, construída por contraste e fundada numa teoria da predica-

\footnotetext{
${ }^{9}$ Sobre a notitia evidens, cf. Perini-Santos (2006).
} 
ção não isenta de oponentes, à questão do porque do apelo de Ockham à abstração. Com efeito, vale salientar o terceiro exemplo de conhecimento fundado na intuição arrolado anteriormente, "um corpo é branco", e perceber que ele não foge à leitura existencial proposta por Ockham. Para ele, trata-se de uma frase que, na medida em que é verdadeira, significa a existência do que é significado tanto pelo sujeito, "um corpo", quanto pelo predicado, "um algo branco", e que dá a saber que ambos se referem a um único item, que existe no tempo da intelecção e que é, ao mesmo tempo, um corpo e branco ${ }^{10}$.

Evidentemente, no âmbito de uma análise do que é veiculado pela proposição, nem toda teoria vê com bons olhos a tese de que na predicação vem afirmada a existência do que é significado pelo termo-sujeito. Tampouco Ockham é do parecer que toda proposição deva ser interpretada como tendo a intenção de alegar a existência do que é significado por seu termo-sujeito: "Aristóteles é do parecer que $p$ " pode, é claro, ser corretamente pensada e proferida nos dias de hoje. Com efeito, o que resulta do quadro ockhaminano com relação a proposições contingentes é a incapacidade de se determinar se há ou não comprometimento existencial com base numa análise puramente formal, por meio, por exemplo, da distinção entre segundo e terceiro adjacente. Dependendo de como foram adquiridos seus termos, uma mesma proposição pode possuir ou não comprometimento

\footnotetext{
${ }^{10} \mathrm{O}$ dossiê da questão sobre o importe existencial de proposições de tertium adiacens remonta até pelo menos o De interpretatione de Aristóteles (16b20-25, 19b19-26 e 21a18-28). Para uma visão geral, cf. Whitaker (1996) e Nuchelmans (1992). Bäck (2000) oferece uma leitura da predicação aparentemente próxima à de Ockham e que no ambiente medieval corresponderia também à posição de Avicena (cf. BÄCK 1987). Tomás de Aquino, Perih. II.1 (AQUINO 1989) parece oferecer uma interpretação alternativa. Sobre o tema, cf. Landim Filho (2009a e 2009b) e Bäck (2003).
} 
existencial. Os casos em que ocorre tal comprometimento são aqueles em que a aquisição dos termos corresponde à intelecção direta e intuitiva de singulares. Resta, nesse quadro, justamente pela abstração, esclarecer o distintivo de casos em que a aquisição dos termos não é suficiente para que se esteja certo do valor de verdade das proposições contingentes que a partir deles se podem formar:

[...] a cognição abstrativa é compreendida como aquela que abstrai da existência e da não existência e de outras condições que, de modo contingente, convêm à coisa ou são predicadas da coisa. [...] É aquela em virtude da qual, acerca de uma coisa contingente, não pode ser sabido de modo evidente se existe ou não existe. E é desse modo que a cognição abstrativa abstrai da existência e da não existência, pois por ela não se pode saber com evidência nem de uma coisa existente que existe, nem de uma coisa não existente que não existe. (OCKHAM 1967-1986, I, 31-32)

Assim como passamos naturalmente da cognição intuitiva à formulação e assentimento a um juízo contingente e existencialmente comprometido, realizamos também, segundo Ockham, um passo suplementar, que permanece restrito à primeira operação do intelecto. Desconsideramos o importe existencial embutido na apreensão intuitiva e dele abstraímos e apreendemos os termos de um modo que não nos inclina a formar ou assentir a uma proposição contingente. Para Ockham, trata-se aqui de um passo naturalmente dado pelo intelecto e cuja causa imediata não está nas coisas, mas na própria cognição intuitiva (cf. OCKHAM 1967-1986, V, 257). É desde esse viés que, segundo ele, se vê corretamente determinado o sentido da tradicional ideia de que "o intelecto abstrai do aqui e do agora" ${ }^{11}$, uma expressão que exporia uma possibilidade - a de abstrair da natural apreen-

\footnotetext{
${ }^{11}$ Cf., p. ex., Tomás de Aquino, De malo q. 16, a. 7, ad5 (AQUINO 1982).
} 
são do concreto - e não um limite da faculdade intelectual humana (OCKHAM 1967-1986, I, 64).

A legitimação ockhamiana da abstração privilegia, assim, em detrimento de uma fundamentação por meio de uma psicologia descritiva da cognição, uma estratégia que se assemelha ao que usualmente se chama de argumento transcendental ou regressivo. Trata-se de um modelo de argumentação em que o recurso a certas noções é justificado pela análise das condições de possibilidade de um determinado aspecto de nossa experiência: se certa prática é possível, é então legítimo aceitar-se o conjunto de conceitos ou princípios por ela necessariamente exigidos (cf. Chauvier 2000). No caso em questão, a análise do conhecimento fundado apenas na intuição se revela insuficiente para justificar a possibilidade concreta de formação de proposições contingentes às quais não nos vemos naturalmente inclinados a assentir.

\section{7.}

Um último tópico permanece ainda problemático no procedimento ockhamiano: se é verdade que a expressão "o intelecto abstrai do aqui e do agora" respalda uma abordagem da abstração como procedimento pelo qual é deixado de lado o comprometimento existencial naturalmente atrelado às nossas proposições. Isso, contudo, parece ainda insuficiente para que se explique a abstração como um procedimento pelo qual se constituem noções universais. Nesse sentido, a justificação ockhamiana da abstração poderia permanecer alvo de uma leitura que a interpretaria como um procedimento meramente parcial, incapaz de esclarecer o ponto-chave da clássica operação abstrativa e sustentado 
unicamente pela necessidade, imposta por uma idiossincrática teoria da proposição, de explicar como proposições de terceiro adjacente podem ser existencialmente neutras.

O tratamento desse problema na obra de Ockham não é isento de dificuldades e não está descartado que seus textos reflitam transformações e apresentem enfoques distintos ao longo do tempo (cf. PANACCIO 1992, 69). Um estudo aprofundado desse processo, de suas facetas e dos motivos que, a cada passo, o teriam levado a formulações no mínimo ligeiramente diferentes, permanece por ser escrito. $\mathrm{O}$ que pode ser feito no âmbito da presente investigação é propor uma breve análise de um texto que possui a peculiaridade de conter o registro mais tardio da posição de seu autor sobre o tema.

Trata-se de uma das questões quodlibetales de Ockham, situadas no período final de seus escritos lógico-filosóficos (redigidas em 1322-23, revisadas em 1324-25) (OCKHAM 1967-1986, IX, 72-78). A questão investigada nos é familiar: "se o primeiro conhecido pelo intelecto segundo a primazia da geração é o singular”. Em seu encaminhamento de resposta - positiva, evidentemente - Ockham adianta certas teses acerca do conhecimento, formulando a última delas nos seguintes termos: "[...] digo que a primeira cognição abstrativa simples segundo a primazia da geração não é uma cognição própria do singular, mas é amiúde uma cognição comum; na verdade, o é sempre” (OCKHAM 1967-1986, IX, 74).

A primeira cognição abstrativa consiste naquela em que com respeito à intuitiva se abstraiu o comprometimento existencial apenas. Tal cognição, segundo a passagem, já consiste numa cognição comum. Numa palavra, abstração da existência implica por si só em ganho de universalidade. 
Assim, em sendo correta tal leitura, não haveria motivo para se construir, à parte do que já funciona como justificação, uma prova à parte do estatuto universal da apreensão abstrativa.

Dessa aproximação entre abstração da existência e ganho de generalidade resulta que a singularidade da cognição intuitiva não pode provir de seu conteúdo. Afinal, a operação de abstração da existência não operaria sobre este. Tal singularidade, de acordo com Ockham (1967-1986, IX, 76), provém unicamente da relação causal única e insubstituível da cognição intuitiva com um determinado indivíduo. Abstrair, portanto, torna-se uma operação de destemporalização, que ocorre quando o intelecto quebra a cadeia causal que une um termo apreendido intuitivamente à sua causa. Talvez tal teoria, em que o conteúdo epistêmico veiculado pela intuição sensorial, pela intuição intelectual e pelo conteúdo abstrato mantém-se inalterado, seja vista por muitos - por Peter Geach (2001), por exemplo - como um tipo de abstracionismo fadado ao fracasso. Para Ockham, porém, trata-se de um modo de, mantendo-se fiel ao projeto aristotélico, não criar uma distância entre sujeito e objeto, uma distância que, por mais que se tente a posteriori contornar, persistirá em tocar adiante seu lento trabalho de erosão dos caminhos de acesso humano às coisas mesmas.

Abstract: Abstraction was traditionally considered an essential element of any theory of cognition that denied that we are able to have an immediate intellectual apprehension of material things. From an historical point of view, however, this scenario of alternative - either abstraction or immediate intellectual apprehension of material things - was not assumed by several authors of the $14^{\text {th }}$ century. The aim of the present study is to elucidate how and why one of these authors, William of Ockham (ca. 1285-1347), employed in his theory on the mechanisms of human cognition both intuition and abstraction. In order to carry out this project, several texts of Ockham and his interpreters will be analyzed. 
Keywords: Abstraction, intuition, William of Ockham.

\section{REFERÊNCIAS}

AQUINO, T. Expositio libri Peryermeneias. Roma/Paris: Comissio Leonina/Vrin, 1989.

- Quaestiones disputatae de Malo. Roma/Paris: Comissio Leonina/Vrin, 1982.

- Quaestiones disputatae de Veritate. Roma: Comissio Leonina, 1970.

. Scriptum super sententiis Magistri Petri Lombardi. Paris: Vivès, 1871-1880.

BÄCK, A. Aquinas on predication. In: BRAAKHUIS, H. A. G. et al. (ed). Aristotele's Peri hermemeias in the Latin Middle Ages. Essays in the Commentary Tradition. Groningen/Haren: Ingenium Publishers, 2003. p. 321-338.

- Avicenna on existence. Journal of the History of Philosophy, v. 25, p. 351-367, 1987.

- Aristotle's Theory of Predication. Leiden: Brill, 2000.

BÉRUBÉ, C. La connaissance de l'individuel au moyen âge. Montréal/Paris: Presses de l'Université de Montréal/Presses Universitaires de France, 1964.

BOEHNER, P. The notitia intuitiva of non-existens according to William Ockham. Traditio 1, p. 223-75, 1943.

CHAPPELL, V. Locke's theory of ideas. In: Id. (ed.). The cambridge companion to Locke. Cambridge: Cambridge University Press, 1994. p. 26-55. 
CHAUVIER, E. (ed.). La querelle des arguments transcendantaux. Cahiers de Philosophie de l'Université de Caen, n. 35, 2000.

DAY, S. J. Intuitive cognition. A key to the significance of later Scholastics. St. Bonaventure, N.Y.: The Franciscan Institute, 1947.

GEACH, P. Mental acts. Their content and their objects. South Bend: St. Augustine Press, 2001.

JOLLEY, N. Locke. His philosophical thought. Oxford: Oxford University Press, 1999.

KANT, I. Manual dos cursos de lógica geral. Campinas/Uberlândia: Editora Unicamp/Edufu, 2002.

KARGER, E. Ockham's misunderstood theory of intuitive and abstractive cognition. In: SPADE, P. V. (ed.) The cambridge companion to Ockham. Cambridge: Cambridge University Press, 1999. p. 204-226.

KLUBERTANZ, G. P. St. Thomas and the knowledge of the singular. The New Scholasticism, n. 26, p. 135-166, 1952.

KRETZMANN, N. Sensus compositus, sensus divisus, and propositional attitudes. Medioevo, n. 7, p. 195-229, 1981.

LANDIM FILHO, R. Predicação e existência na semântica clássica. In: Id. Questões disputadas de metafísica e de crítica do conhecimento. São Paulo: Discurso, 2009a. p. 339. 371.

. Predicação e juízo em Tomás de Aquino. In: Id. Questões disputadas de metafísica e de crítica do conhecimento. 
São Paulo: Discurso, 2009b. p. 373-406.

LOCKE, J. An essay concerning human understanding. Oxford: Clarendon Press, 1975.

LOWE E. J. Locke on human understanding. New York: Routledge, 1995.

MAIERÚ, A. Sensus compositus/sensus divisus (secoli XIIXIV). In: BIANCHI, L. (ed.) Sensus/Sensatio. VIII Colloquio internazionale del lessico intellettuale europeo. Firenze: Leo S. Olschki, 1996. p. 121-140.

MARÉCHAL, J. Le point de départ de la métaphysique. Leçons sur le développement historique et théorique du problème de la connaissance. Cahier I: De l'antiquité à la fin du moyen âge: La critique ancienne de la connaissance. Bruges/Paris: Beyaert/Alcan, 1922 [Nas citações foi seguida a quarta edição da obra (Paris: Desclée De Brouwer, 1964)].

NUCHELMANS, G. Secundum/tertium adiacens. Vicissitudes of a logical distinction. Amsterdam et al.: NoordHollandsche, 1992.

OCKHAM, G. Guillelmi de Ockham Opera Philosophica. 7 vols. St. Bonaventure, N.Y.: The Franciscan Institute, 1974-1988.

. Guillelmi de Ockham Opera Theologica. 10 vols. St. Bonaventure, N.Y.: The Franciscan Institute, 1967-1986.

PANACCIO, C. Intuition, abstraction et langage mental dans la théorie occamiste de la connaissance. Revue de Metaphysique et de Morale, n. 1, p. 61-81, 1992. 
PERINI-SANTOS, E. La théorie ockhammiene de la connaissance évidente. Paris: Vrin, 2006.

PUTALLAZ, F.-X. Le sens de la réflexion chez Thomas d'Aquin. Paris: Vrin, 1991.

TWEEDALE, M. M. Locke on universals: the fruit of Ockham's dilemma? In: BROWN, S. (ed.). Meeting the minds. The relations between Medieval and Classical Modern European Philosophy. Turnhout: Brepols, 1998. p. 235-244.

WEBER, E. Abstractio (abstraction) (lat. méd.). In: AUROUX, S. (ed.). Les notions philosophiques. Dictionnaire. v. II.1. Paris: Puf, 1990. p. 9-11.

WHITAKER, C. W. A. Aristotle's De interpretatione. Contradiction and Dialectic. Oxford: Oxford University Press, 1996. 